\title{
El INICIO de IXTAPAN DE LA SAL COMO EMPORIO tURístico
}

\author{
Graciela Cruz JimÉnez \\ gracicj@hotmail.com \\ Centro de Investigación y Estudios Turísticos \\ Universidad Autónoma del Estado de México \\ Cecilia Cadena Inostroza \\ ccadena@cmq.edu.mx \\ El Colegio Mexiquense
}

\begin{abstract}
Este documento aborda los principales hechos correspondientes a la primera etapa del desarrollo turístico en Ixtapan de la Sal, uno de los destinos más importantes del Estado de México, cuya evolución está asociada con las aguas termales. El análisis está basado en el enfoque de redes de política pública y tiene un fuerte sustento en información documental y en entrevistas con actores vinculados con esa actividad. Los principales hallazgos evidencian asimetrías de poder entre los sectores público, social y privado en Ixtapan de la Sal durante el periodo analizado, por lo cual se concluye que los actores con mayores recursos de distinto tipo influyeron en el rumbo de este destino turístico.
\end{abstract}

Palabras clave: Ixtapan de la Sal, turismo, redes de política pública, evolución, destino.

\section{The StaRT OF IXTAPAN DE La SAL AS a tOURISM EMPORIOUM}

This document addresses the main events of the first development stage in Ixtapan de la Sal as a tourism destination where the local hot springs are associated to its evolution and make it one of the most important destinations in Estado de Mexico. This analysis is based on the approach of public policy networks, and it has a strong support in documentary information and interviews with actors related to this activity. The main findings show power asymmetries among the public, social, and private sectors of Ixtapan de la Sal during the analyzed period; therefore, it is concluded that those actors with the most resources influenced the development course of this tourism destination.

Keywords: Ixtapan de la Sal, tourism, policy networks, evolution, destination.

Fecha de recepción: 5 de abril de 2018. Fecha de aceptación: 7 de junio de 2018

CÓMO CITAR: Cruz, G. y Cadena, C. (2018). El inicio de Ixtapan de la Sal como emporio turístico. Dimensiones Turísticas, 2(3), 25-47. https://doi.org/10.47557/PKYS8544 


\section{Introducción}

$\mathrm{H}$

oy en día el turismo ha cobrado fuerza como una alternativa para contribuir al rescate y preservación de los recursos naturales y culturales de la comunidad receptora, bajo el supuesto de que beneficia tanto a sus habitantes como al propio visitante, al ofrecerle un destino más conservado en lo que respecta a su patrimonio natural, histórico y cultural.

Esta dinámica contrasta con la de décadas atrás, cuando el acento estaba puesto exclusivamente en la obtención de ganancias económicas, sin que ello signifique que esta práctica haya cambiado en su totalidad; todavía es común que los procesos decisorios favorezcan los intereses de los más poderosos en perjuicio de los pobladores y de su entorno.

Tal es el caso de Ixtapan de la Sal, uno de los principales sitios turísticos del Estado de México, donde la mayoría de los habitantes de su cabecera municipal dependen directa o indirectamente de esta actividad, que ha sufrido una transformación significativa con el correr de los años, que no podría explicarse sin entender su pasado, incluyendo a los actores que influyeron en el proceso.

En la década de los cuarenta del anterior siglo, el empresario Arturo San Román Chávez empezó a construir en ese lugar su emporio basado en un turismo de salud encaminado a la atención de problemas físicos a partir de las aguas termales. En la actualidad la oferta de Ixtapan de la Sal está concentrada en un parque acuático, un spa, el fraccionamiento turístico-residencial Grand Reserva y el hotel Ixtapan; todos estos servicios a cargo de los herederos de ese personaje.

Diversos factores contribuyeron en su conjunto a moldear el actual perfil turístico de la localidad: en un marco general, la reconfiguración del Estado mexicano, cuya apertura a la que hace alusión Porras (2012, p. 13) propició la redefinición en ciertos ámbitos de las funciones tradicionales de los actores gubernamentales y no gubernamentales. En ese contexto y en el ámbito local, se integraron asociaciones de prestadores de servicios turísticos y con ello aparecieron nuevos actores.

El avance en las telecomunicaciones y los cambios en la política turística también fueron determinantes en las relaciones que se gestaron entre diferentes personajes, las cuales influenciaron el proceso decisorio en ese destino. Son precisamente estos vínculos los que fundamentan el enfoque de redes de política pública (ERPP), que da sustento teórico al caso aquí expuesto.

Durante la primera etapa del desarrollo turístico de Ixtapan de la Sal fueron identificados dos cursos de acción; estos se conciben como los sucesos o eventos compuestos por distintos actos, cuyas características propiciaron relaciones entre diversos personajes, quienes con sus recursos, dependencias y lazos de cooperación lideraron las acciones turísticas.

Estos cursos de acción, que tuvieron lugar entre 1930 y 1979, corresponden respectivamente al arrendamiento del balneario de San Gaspar y a la confrontación por las aguas termales; este último es el más ríspido y propicio para el análisis, ya que incluye la disputa 


\section{G. Cruz Jiménez · C. Cadena Inostroza}

por los borbollones de Santa Catarina y la concesión de las aguas termales de San Gaspar, que fueron el centro de la oferta turística.

Para analizarlos y explicarlos, se presenta secuencialmente el sustento teórico de las redes de política pública, cuyo enfoque sirvió para guiar la investigación "El turismo como elemento de conflicto y acuerdo en las redes de política pública de Ixtapan de la Sal”, de la cual se deriva este artículo. Se aborda la metodología utilizada y se ofrece una panorámica general sobre Ixtapan de la Sal que sirve de contexto a los referidos cursos de acción relativos a su primera etapa de desarrollo turístico; de su descripción y análisis se derivan los resultados y las conclusiones.

\section{Las redes de política pública como base teórica}

En las últimas décadas ha crecido el interés entre la comunidad científica por el estudio de las políticas públicas; según Van Meter y Van Horn (2003, p. 99), constan de aquellas acciones efectuadas por individuos (o grupos) públicos y privados, tendientes a la consecución de objetivos previamente decididos a partir de un problema público. Este cobra tal categoría cuando las necesidades, intereses y proyectos son de alcance general (Aguilar, 2003, p. 29).

Por tanto, en un primer momento estas inquietudes corresponden a la agenda pública que, a diferencia de la gubernamental, se inclina a ser más general y abstracta. Los asuntos presentan una formulación genérica y aún se encuentran en su fase de formación de una problemática que afecta a un grupo considerable de personas (Montecinos, 2007, p. 328). Una vez que se fijan en la agenda de gobierno, el ente público genera una política para resolverlos.

Con base en ello y según Franco (2013, p. 88), las políticas públicas son acciones de gobierno con objetivos de interés público que surgen de decisiones sustentadas en un proceso, para la atención de problemas públicos específicos, en donde la ciudadanía participa en la definición de problemas y soluciones. Su mayor fortaleza analítica y disciplinaria (Hernández, 2015) radica en la posibilidad, a partir de este enfoque, de operacionalizar múltiples conceptos y estudiar muy diversos fenómenos sociales; el turístico sería uno de ellos.

En términos teóricos, estas políticas deben estar formadas por quienes participen de ellas, independientemente de que emanen de un ente público; sus amplios alcances relacionados con la participación, la democracia y la corresponsabilidad, entre otros elementos, les asignan un peso importante, pues de su implementación depende en gran medida la orientación que toma determinada acción. Sin embargo, se ha comprobado (Cruz, 2014; Cadena y Cruz, 2006) que son las interacciones entre personajes vinculados con esas políticas las que en realidad configuran sus resultados y no los lineamientos normativos bajo los cuales son diseñadas. Con base en este argumento, la hechura de las políticas responde a la interacción entre varios actores para asegurar la satisfacción de sus intereses (Klijn, 1997, p. 22). 
En estos aspectos está centrado el ERPP, el cual explica cómo a pesar de ciertos elementos que en teoría podrían favorecer o afectar determinadas acciones estas toman un rumbo diferente según la manera en que se relacionen los actores a partir de lo que Meny y Thoenig (1992, p. 103) denominan juego político: aquel que estos despliegan para hacer prevalecer sus propósitos y durante el cual ejercen sus recursos de distinta naturaleza para formar vínculos de cooperación o dependencia con otros, lo que genera una interacción positiva o negativa entre ellos. Esto influye en la conducción de decisiones y acciones, en este caso las turísticas (Cruz, Serrano-Barquín, Mejía, Mejía y Reza, 2010, p. 380). Por lo tanto, en las redes de política pública el análisis está enfocado en los actores que participan en su formación e implementación.

El esfuerzo intelectual y práctico ha de centrarse en sus condiciones de consenso, corrección y factibilidad en su formación, implementación, impacto y evaluación, en averiguar y depurar la manera en que ciertos problemas sociales o grupales devienen públicos y se insertan en la agenda de gobierno (Aguilar, 2007, p. 22). A la vez, el tipo de interdependencia y la convergencia o divergencia de intereses de los miembros que constituyen una red son los elementos a partir de los cuales Zabaleta (2006, pp. 47-48) clasifica estas redes en formales e informales; las primeras no establecen una organización clara (reglas, jerarquías, procedimientos, etc.), pero son capaces de formular políticas públicas mediante interacciones menos rígidas.

En tanto, las informales pueden surgir a partir de la presión de interés en torno a cierta política que busca influir en ella; estas redes se limitan a contactos entre los integrantes de diferentes organizaciones mediante interacciones informales -llamadas telefónicas, reuniones ad hoc, intercambio de información, etc.-. En ambos casos, la toma de decisiones es muy variada y dependerá en gran medida de la composición de la red (número y tipo de personajes, intereses y expectativas de cada uno); el tiempo de vida esperado de la red, el tipo y el número de funciones determinará si esta tenderá a formalizarse (Zabaleta, 2006, pp. 48, 54-55). En suma, estas redes son una representación abstracta de la realidad.

Además de la exploración documental sobre redes y políticas públicas, fueron revisados los postulados de las teorías interorganizacional y de ciencia política que sirven de base al enfoque con el que fue construido el marco teórico que soporta la investigación de la cual se deriva este artículo, el cual pone de relieve que el turismo representa, en términos investigativos, un área promisoria en el terreno político, pues alrededor de él se agrupan personajes públicos, sociales y privados con objetivos e intereses que bien pueden ser comunes o divergentes. Es a lo que Hernández (2015) llama actores heterogéneos, por tratarse de diversos tipos de autoridades, niveles de gobierno u origen de los recursos.

\section{El ERPP para el análisis de una realidad}

Con base en el ERPP fue desarrollada la investigación empírica siguiendo la propuesta metodológica de Cruz (2014), quien define como variables de análisis los objetivos, intereses, 


\section{G. Cruz Jiménez · C. Cadena Inostroza}

recursos, dependencia, cooperación e intensidad de interacción entre los participantes, en este caso, de la red que se formó durante los dos cursos de acción abordados.

Por tratarse de un periodo de análisis entre 1930 y 1979, la investigación tuvo un fuerte soporte documental, principalmente en archivos municipales y estatales. Además de aportar datos sobre aspectos importantes vinculados con el turismo, la información permitió identificar personajes cuya intervención fue relevante durante ese periodo; sin embargo, dado que la primera fase de desarrollo turístico de Ixtapan de la Sal tuvo lugar hace varias décadas, ninguno de ellos sobrevive. Por tanto, un segundo ejercicio consistió en seleccionar actores capaces de aportar información sobre estos, pero también datos más actuales en torno al destino.

Los informantes clave fueron el presidente municipal, el cronista, funcionarios municipales de la Dirección de Turismo, y pequeños y medianos hoteleros. Para abordarlos fueron diseñados guiones de entrevistas semiestructuradas con preguntas sobre las referidas variables (objetivos, intereses, recursos, dependencia, cooperación e intensidad de interacción entre los participantes en la red) que las vincularan con los personajes que tuvieron un papel preponderante durante los dos cursos de acción.

Los testimonios recabados fueron contrastados con la información documental a fin de confrontar las ideas, complementarlas o descartarlas, para lograr una interpretación más ajustada a la realidad. ${ }^{1}$ A partir de ello fueron diseñadas matrices relacionales cuyo análisis facilitó determinar la fortaleza o debilidad de los vínculos entre actores, que a su vez permitió establecer su influencia en la red y, por ende, en el proceso decisorio de Ixtapan de la Sal.

Las matrices fueron nueve por cada curso de acción; la primera tuvo un carácter meramente cualitativo, ya que concentró los objetivos e intereses de los actores objeto de estudio, así como el sector (público, social o privado) al que pertenecían. Esta matriz sirvió de base para las siguientes dos que, al igual que las restantes, tuvieron una naturaleza cuantitativa. Una abordó su compatibilidad de objetivos y la otra su compatibilidad de intereses. Para ambas fueron asignados los siguientes valores: compatibilidad alta +2 ; compatibilidad media +1; compatibilidad baja -1; compatibilidad nula -2 .

La cuarta matriz correspondió a los recursos puestos en juego por actor. Los valores asignados fueron: recursos altos +2 ; recursos medianos +1 ; recursos bajos -1 ; recursos nulos -2. La quinta analizó la dependencia entre actores, y los valores fueron: sin dependencia +2 ; dependencia baja +1; dependencia mediana -1 ; dependencia alta -2 .

Mediante la sexta matriz fue abordada la cooperación entre los integrantes de la red, a partir de los valores: cooperación alta +2; cooperación mediana +1; cooperación baja -1; cooperación nula -2 .

La séptima matriz concentró el promedio obtenido por actor en el curso de acción objeto de análisis; en la octava se colocaron los valores de ponderación por cada una de las

'En el cuerpo del texto, cuando se hace referencia por primera vez a un actor, se incluye su cargo y el nombre completo con las iniciales correspondientes, con las cuales se le identifica sucesivamente. 
variables de análisis correspondientes a las seis matrices relacionales. La novena matriz incluyó el factor de ponderación por variable de análisis, lo que arrojó el puntaje final por actor y sector.

Con esos resultados fue esbozado un modelo de red de política pública para esquematizar el predominio de sus participantes, así como el tipo e intensidad de relación entre sus integrantes, la cual se representa gráficamente en el apartado de resultados.

\section{Panorámica de Ixtapan de la Sal}

El municipio se localiza en la parte sur del Estado de México, a 135 kilómetros al suroeste de la Ciudad de México; colinda con cinco municipios mexiquenses y con el estado de Guerrero (H. Ayuntamiento de Ixtapan de la Sal, 2016, p. 11). El nombre de Ixtapan de la Sal es de origen náhuatl y significa "En la sal" o "Sobre la sal".

Desde la época prehispánica las aguas termales han representado un aspecto relevante en la cabecera municipal. Hacia 1394, los indígenas provenientes de las costas del Pacífico le informaron al emperador acerca de la existencia de agua caliente, pero, sobre todo, que al evaporarse el agua de los manantiales se formaba sal, artículo muy apreciado porque se comercializaba mediante trueque (Arizmendi, 1999a, p. 4).

Las propiedades terapéuticas del sitio se relacionaron con el temazcalli -casa de baño de vapor-, lo cual alentó las visitas de emperadores, con fines de reposo y descanso (Becerril, 1988, p. 23). Durante la Conquista, las autoridades virreinales fueron notificadas sobre la existencia de estas aguas y los beneficios físicos que generaban (Hernández, 2001, p. 47).

Iztapan tuvo un papel estratégico dentro de la Provincia de la Plata, como fue denominada la primera región minera de la Nueva España, conformada por cuatro comarcas: Temazcaltepec, Sultepec, Tasco y Zacualpan; a esta última pertenecía Ixtapan. Algunos factores que contribuyeron a tal situación fueron su cercanía con la ciudad de México y las minas de Zacualpan y Tasco; asimismo su fertilidad tanto para la agricultura como para la ganadería, y la producción de sal desde la época prehispánica que se comercializaba en la región (García, 2000, pp. 31, 53-54).

Con el paso de los años, en Ixtapan de la Sal se registró un flujo de metaleros y comerciantes españoles, mestizos e indios, proveedores de diversos productos, por lo cual las "ventas" o posadas tuvieron un papel preponderante como negocio de hospedaje (García, 2000, p. 61). Sin embargo, hacia 1860 en ocasiones no encontraban alojamiento en ninguno de los mesones de la región, que eran casas particulares acondicionadas (Hernández, 2001, pp. 52-53); por lo tanto, surgieron al menos tres casas de huéspedes para atender tanto esta demanda, como la necesidad de alimentación y descanso de los animales que transportaban cargamentos de oro y plata.

Los españoles vieron en el hospedaje un negocio alterno a la agricultura y la ganadería (González, 2004, p. 156); los permisos para estos establecimientos generalmente fueron otorgados a personajes ligados con la élite novohispana que tenían intereses en Ixtapan 


\section{G. Cruz Jiménez · C. Cadena Inostroza}

de la Sal; el primero del que se tiene constancia fue autorizado en 1576 a don Francisco Gómez de Saavedra (Ricaurte, 2001, pp. 65-66).

De lo anterior se concluye que, hasta ese momento, aunque eran apreciadas las propiedades de las aguas termales, no motivaron importantes desplazamientos para su aprovechamiento y, por lo tanto, tampoco produjeron algún efecto, como sí lo hizo la actividad comercial que alentó la aparición de sitios para el descanso de metaleros y vendedores, pero aún no para turistas. Hubo otros factores, como la construcción del ferrocarril (cuya estación estaba localizada en la población de Atlahuaca, cerca del vecino municipio de Tenango del Valle), que motivaron la instalación de más posadas entre 1860 y 1870 (Arizmendi, 1999b, p. 66). En esos años empezaba a gestarse de manera incipiente la oferta turística basada en el aprovechamiento de las aguas termales.

Es de resaltar que en las fuentes documentales existe una "laguna" de información de casi un siglo en materia de hotelería en este sitio, que abarca de 1870 a la segunda mitad del siglo xx, lo cual Ricaurte (2001, p. 71) atribuye a que en 1912 el archivo histórico municipal fue incendiado por un grupo de zapatistas durante la Revolución mexicana, de modo que no se cuenta con documentos anteriores a esa época.

Hasta antes de 1940 la economía del municipio estaba sustentada en las actividades primarias (Martínez, 1997, p. 63), a pesar de que una década atrás varios campesinos de las comunidades rurales comenzaron a migrar hacia la cabecera municipal para insertarse en actividades relacionadas con el turismo, ya fuera mediante empleos directos o indirectos asociados principalmente con el comercio (Ricaurte, 2001, pp. 77-79, 81, 103). Entre las décadas de los treinta y cuarenta, solo 1 \% de la población se dedicaba al turismo, pero en los cincuenta la cifra aumentó a 12 \% y observó un crecimiento continuo (Martínez, 1997, pp. $35,63)$.

En los últimos años, según el exalcalde Cesáreo Antonio Domínguez Díaz (CADD), 90 \% de la población de la cabecera municipal se ha beneficiado directa o indirectamente de esta actividad. De acuerdo con el Censo de Población y Vivienda (Instituto Nacional de Estadística y Geografía, 2010), la población de Ixtapan de la Sal asciende a 33541 personas; casi la mitad está concentrada en la cabecera municipal.

Además de su belleza paisajística derivada de una amplia variedad de especies vegetales, producto de su temperatura media anual de $17.9 \stackrel{\circ}{ }$ C, cabe señalar que Ixtapan de la Sal cuenta con recursos culturales, entre ellos el uso del barro y la madera para elaborar productos ornamentales y utilitarios, así como la preparación de dulces de pipián; también con algunos recintos religiosos como las parroquias de la Asunción de María y de Santa Ana Xocuca. Pese a este potencial, tales recursos no han sido capitalizados en su primera ni en su segunda fase de desarrollo turístico, para integrarlos como atractivos o productos turísticos.

Antes de alcanzar el rango de centro turístico por excelencia, la localidad observó una evolución turística; su primera etapa de desarrollo fue determinante en este proceso. 


\section{Primera etapa de desarrollo turístico}

\section{1 El arrendamiento del balneario de San Gaspar}

El primer curso de acción que tuvo una amplia influencia en esta etapa fue el arrendamiento del balneario de San Gaspar, pues sentó las bases para que, en años posteriores, sus aguas termales fueran concesionadas a uno de los personajes con mayor influencia en ese destino turístico: Arturo Alfredo San Román Chávez.

En 1850 un italiano construyó el primer balneario público en los borbollones de San Gaspar, el cual funcionó hasta 1910, cuando fue cerrado a causa de la Revolución (Arizmendi, 1999b, pp. 6-7). En aquel entonces, según el excronista Luis René Domínguez Arizmendi (LRDA), el gobierno municipal arrendaba el balneario y también administraba sus aguas termales.

Quizá debido a la falta de evidencia documental a la que se hizo referencia, el siguiente dato, sin que exista más información al respecto, corresponde a los años treinta, en que ese balneario fue arrendado a Erasmo Hernández, quien perteneció a una familia de políticos "a la buena o a la mala", por lo que, en su momento, al tener recursos (medianos), tanto económicos como políticos, obtuvo con cierta facilidad la renta del balneario (LRDA). Sin embargo, la seguridad de sus ingresos económicos dependía de mantener el contrato pactado con el gobierno municipal.

En 1931, a instancias del gobernador Filiberto Gómez, se realizó una campaña publicitaria del destino (Hernández, 2001, p. 53) y, un año después, el químico Rafael Ortiz Mena determinó que las aguas termales combatían el reumatismo articular, por lo cual eran útiles para diversos padecimientos (Castillo, 1995, p. 48); ambas acciones propiciaron que aumentara el flujo de personas que deseaban beneficiarse de estas. Flores (1987, pp. 32-34) da cuenta de ello cuando refiere que por el acceso principal a la cabecera municipal pasaba rumbo al balneario un gran número de enfermos a pie, con muletas o en carritos, con la esperanza de encontrar alivio para sus males en sus aguas milagrosas.

Casi al mismo tiempo, en medio del descontento de la población -por no ser oriundo del lugar-, el ayuntamiento de Ixtapan de la Sal le arrendó el inmueble al guanajuatense José Reynoso mediante un contrato avalado por el congreso estatal (H. Ayuntamiento de Ixtapan de la Sal, 1931), lo cual ocasionó conflictos sociales (Ricaurte, 2001, p. 72).

Entre 1913 y 1914 ese personaje fue subsecretario de Hacienda y Crédito Público y, más tarde, encargado del despacho. En el Constituyente de 1917 ocupó una curul por el Estado de México en Querétaro y después fue varias veces senador de la República. También se desempeñó como gobernador provisional de Guanajuato y luego se dedicó a negocios particulares, entre ellos el turístico en Ixtapan de la Sal.

Tales cargos no solo le brindaron soporte económico, además le permitieron afianzar relaciones en el ámbito federal, por lo que al tener altos recursos impuso su predominio y le fue concedido el arrendamiento. Él, al igual que Erasmo Hernández, pretendía afianzarse política y económicamente, lo cual él sí pudo concretar al imponer su supremacía. 
Se argumenta que, como diputado federal, José Reynoso llegó “ofreciendo las perlas de la Virgen" por el arrendamiento (LRDA).

Se infiere que las relaciones que formó en sus distintos cargos pudieron haber influido en uno de los objetivos del gobernador Filiberto Gómez: apoyar al empresario para que obtuviera este beneficio y así el mandatario recibiría su apoyo ante cualquier eventualidad que se registrara en Ixtapan de la Sal. Por lo tanto, fue bastante la cooperación entre ambos personajes, pero menor la dependencia del mandatario hacia el empresario, pues aunque se deduce que intercedió a su favor, José Reynoso no era el único aliado del que el Ejecutivo estatal pudo haber dispuesto para concretar su fin. Erasmo Hernández también tuvo una gran dependencia de las decisiones del gobernador para mantener la concesión, lo cual no logró.

Por otra parte, las relaciones que José Reynoso formó en sus anteriores cargos fueron decisivas para que el congreso local avalara el referido contrato de arrendamiento, por lo que a Erasmo Hernández no le quedó más remedio que acatar tal disposición, luego que el entonces alcalde Brignó Tovar le dirigiera un oficio, comunicándole que "por acuerdo de este Ayuntamiento, los baños termales propiedad de este municipio quedan por cuenta del arrendatario Sr. Ing. José J. Reynoso conforme al contrato que tiene celebrado este Ayuntamiento con el expresado". Como resultado, fue nula la compatibilidad de intereses entre José Reynoso y Erasmo Hernández, al igual que la cooperación entre ellos.

Asimismo, el hecho de que Reynoso ya tuviera cierto capital económico, producto de haber establecido el primer hotel en la cabecera municipal, habría influido en su objetivo de ampliar su oferta turística con la obtención del arrendamiento del balneario. Fue él quien gestionó la construcción de una vía para mejorar el acceso a la cabecera municipal, con lo cual se percibe cómo el objetivo de un actor para favorecer el desplazamiento hacia su negocio y consolidar su posición económica y política contribuyó al mejoramiento de caminos, aspecto que tuvo una repercusión más amplia, pues benefició además a otros sectores, como el comercial, y con ello se empezó a modificar el perfil de la localidad.

Al mismo tiempo, el ayuntamiento de Ixtapan de la Sal no era del todo autónomo sobre la renta del balneario, que también estaba supeditada -si no formalmente, sí en la prácticaal gobierno del Estado de México, lo cual reflejaría la alta dependencia de Reynoso hacia el mandatario estatal, cuya decisión acerca del arrendamiento habría sido la definitiva y no la de las autoridades ixtapenses.

El pago del arrendamiento del balneario representaba $15 \%$ sobre las entradas brutas al inmueble, cantidad que beneficiaba directamente al gobierno municipal (Arizmendi, 1999b, pp. 6-7), sin que esté claro en qué rubros fueron aplicados tales recursos. Desde entonces prevalecían prácticas de opacidad, pues aunque el secretario general de gobierno Francisco Carvajal le pidió al presidente municipal darle al Gobierno del Estado de México una copia del contrato de arrendamiento que suscribió con José Reynoso, el alcalde le respondió que "en esta presidencia no existe copia del contrato" (H. Ayuntamiento de Ixtapan de la Sal, 1932). 
El gobierno municipal en funciones en 1932 disponía de pocos recursos, por lo que su objetivo fue fortalecer sus finanzas mediante el porcentaje que le correspondía de ganancia sobre las entradas del inmueble, lo cual concretó gracias a Erasmo Hernández y a José Reynoso, quienes en su momento cumplieron su cometido de obtenerlo en renta, de ahí que los objetivos entre autoridades municipales y particulares tuvieron una alta compatibilidad.

En este mismo sentido, esos actores privados observaron una gran dependencia hacia las autoridades municipales para que les arrendaran el balneario; la dependencia del gobierno hacia ambos fue de la misma magnitud, pues requería rentar el inmueble a quien le garantizara $15 \%$ sobre las entradas brutas. Bajo este argumento los tres concretaron una alta cooperación, ya que mutuamente complementaron sus propósitos. A la vez, a pesar de que los intereses de estos tres personajes eran distintos, puesto que atendían a una naturaleza diferente, se complementaron y, por tanto, fueron de mediana compatibilidad.

En tal acción se refleja la configuración de relaciones de poder, pues en esta situación la concertación entre el gobierno de Ixtapan de la Sal con Erasmo Hernández y José Reynoso obedeció a la expectativa de las utilidades que cada uno de ellos calculó obtener y de ahí derivaron sus estrategias. En el caso del gobierno municipal de Ixtapan de la Sal en 1932, si bien sus recursos financieros eran bajos, disponía de altos recursos normativos, ya que él determinaba a quién le arrendaba el inmueble.

No obstante, en esa época las autoridades municipales estaban supeditadas a los designios de las autoridades estatales y federales, por lo cual eran susceptibles a que sus decisiones no fueran del todo autónomas; el gobierno ixtapense no fue la excepción en cuanto a una posible intromisión sobre quién sería el beneficiario con el arrendamiento, por lo que sus recursos políticos resultaron medianos. El correspondiente a la información fue alto, ya que disponía del conocimiento técnico para realizar la concesión.

Queda claro, en palabras de Aguilar (1992, pp. 29, 33-36), el protagonismo gubernamental que prevalecía. Como se ha demostrado, durante el presente curso de acción los actores centrales en términos reales fueron el gobierno municipal y los dos arrendatarios, independientemente de la intervención del gobernador para favorecer a uno de ellos. Destaca el hecho de que solo dos personajes hayan sido tenidos en cuenta para rentarles el balneario, aunque no se descarta que algunos prestadores del servicio de hospedaje, que para esa época sumaban alrededor de 20, hubieran manifestado su interés por arrendarlo, con lo cual se confirmaría que los dos actores privados con más recursos entonces, en especial financiero y político, resultaron beneficiados.

Es notable también la ausencia de personajes del sector social. A pesar de que había cierta inconformidad entre los habitantes de Ixtapan de la Sal por el arrendamiento del balneario a Reynoso, la magnitud de su descontento no fue importante; se deduce que en parte obedeció a que no estaban organizados, por lo cual sus quejas a título personal no prosperaron. Sin embargo, con el paso del tiempo, los sucesos empezaron a tomar una perspectiva diferente y la molestia del pueblo creció al sentir que era excluido de los beneficios derivados de las aguas termales, que jugó un papel relevante durante el segundo 


\section{G. Cruz Jiménez · C. Cadena Inostroza}

curso de acción que se plantea a continuación (la confrontación por las aguas termales), durante el cual se desarrollaron dos hechos significativos: la disputa por los borbollones de Santa Catarina y el arrendamiento del balneario de San Gaspar.

\section{La confrontación por las aguas termales}

\subsection{La disputa por los borbollones de Santa Catarina}

Desde los años treinta los habitantes de Ixtapan empezaron a manifestarse en contra de que personajes ajenos a la localidad fueran favorecidos con las aguas termales. Erasmo Hernández sí era oriundo de Ixtapan de la Sal, contrario al italiano del que se tiene la primera referencia sobre el arrendamiento del balneario; tampoco lo eran José Reynoso ni Arturo Alfredo San Román Chávez.

Poco después, en los cuarenta, el reclamo popular sobre los beneficios de este recurso alcanzó su punto más álgido, lo cual obligó a la intervención presidencial; como resultado, en un acuerdo firmado el 13 de junio de 1941, el mandatario federal Manuel Ávila Camacho estableció que los borbollones asentados en el barrio de Santa Catarina (conocidos como “El Borbollón de Santa Catarina” y "El Bañito) se reservaran para uso exclusivo y gratuito de los pobladores, por lo tanto, no se podrían entregar a ningún concesionario, ni dictarse medidas que limitaran el aprovechamiento total en su beneficio (Ricaurte, 2001, pp. 7375). El gobernador Isidro Fabela avaló tal disposición y ordenó construir un balneario en los borbollones de Santa Catarina, que eran utilizados de manera muy rudimentaria por los vecinos. Con ello se confirió a los ixtapenses el uso de este recurso, que tenía menores ventajas en cuanto a caudal y ubicación respecto a los de San Gaspar.

A Manuel Ávila Camacho le unía una "vieja y profunda amistad" con el gobernador Isidro Fabela que le rindió frutos importantes a este último (Hernández, 1998, pp. 61, 64). Esa relación se explica por el apoyo que Fabela -quien no pertenecía a la clase política local- dio al proyecto nacional de largo alcance del presidente que lo impuso en el cargo como una forma de evitar que permaneciera en el poder la élite tradicional involucrada en el asesinato del gobernador Alfredo Zárate Albarrán, hecho que ocasionó el descontento del mandatario federal, por lo cual respaldó a Fabela en la creación de su propio equipo de colaboradores para dar continuidad a la administración del político fallecido (Hernández, 1998, pp. 26, 40, 43, 59).

Gracias a la puesta en juego de sus altos recursos políticos, normativos, humanos y de información, el gobernador pudo concretar la disposición presidencial respecto a que ningún particular se beneficiara del uso de los borbollones de Santa Catarina; este decreto fue respaldado por el posterior dictamen de Isidro Fabela sobre el uso gratuito para la población. El gobernador tenía claro que la formación de un estado moderno solo podía alcanzarse, entre otras acciones, pacificando a los grupos, por lo que uno de sus principales propósitos fue abolir la violencia (Hernández, 1998, p. 66).

Aun cuando los objetivos de Isidro Fabela sobre los borbollones de Santa Catarina no buscaban en realidad atender los del pueblo, los habitantes resultaron beneficiados de las 
disposiciones oficiales, por ende, sus objetivos tuvieron una compatibilidad intermedia; no así sus intereses, cuya compatibilidad fue poca, dado que los del mandatario estatal estuvieron centrados en cuestiones totalmente ajenas a los suyos. Pese a ello, se generó de forma involuntaria una cooperación, aunque baja, entre estos dos actores, basada en su pretensión de que las aguas termales de Santa Catarina no fueran concesionadas a particulares.

El pueblo de Ixtapan de la Sal estuvo a expensas de las medidas que adoptó Isidro Fabela en torno a ese problema, por lo que su dependencia hacia él fue alta, aunque, a su vez, este también dependió del pueblo, pero en una proporción mediana, pues si continuaban sus manifestaciones de descontento se rompería el orden social y se pondría en riesgo su proyecto político y económico en ese municipio, por lo cual grupos inconformes con algún asunto podrían secundar el ejemplo de Ixtapan de la Sal.

Paralelamente, en 1941 llegó por primera vez a la localidad Arturo Alfredo San Román Chávez, quien ideó un gran centro turístico medicinal, pues "se dio cuenta de la bondad de sus aguas termales, su maravilloso clima y sus hermosos lomeríos” (Guadarrama, 2004). Desde entonces este personaje, con importantes vínculos con la clase política, empezó a tejer puentes que le permitieran cumplir su propósito de obtener en concesión las aguas termales de San Gaspar, lo cual suscitó la inconformidad entre los pobladores que reclamaban para ellos los beneficios de esas aguas.

Hacia 1944, durante este segundo curso de acción, el empresario San Román Chávez también gestionó la concesión de los borbollones de Santa Catarina, lo cual le permitiría posicionar económica y políticamente a su familia. Esta petición generó hostilidad entre el pueblo, pero además el gobierno municipal de 1944 entabló una disputa legal para que tal solicitud no prosperara.

El objetivo de las autoridades de Ixtapan de la Sal era que, con base en el referido dictamen gubernamental, los borbollones de Santa Catarina no fueran concesionados a particulares, lo que denota la nula compatibilidad de objetivos e intereses con el empresario, tanto por parte del ayuntamiento como de los ixtapenses; por el contrario, los objetivos de estos dos últimos actores fueron altamente compatibles, contrario a la baja compatibilidad de sus intereses, ya que los del gobierno eran conservar los ingresos derivados del uso de los borbollones, y los de la comunidad, seguir utilizando las aguas como un recurso colectivo.

Pese a ello, la cooperación entre ambos fue mediana, al igual que la dependencia del gobierno municipal hacia el pueblo, pues requería que los habitantes continuaran manifestando su inconformidad; de esta forma, las autoridades tenían un respaldo para presionar que se hiciera efectivo el citado decreto. Por su parte, el pueblo observó una alta dependencia hacia el ayuntamiento, porque el hecho de que esas aguas no pasaran a manos de San Román estribaba en que el gobierno ganara la querella que entabló en su contra. Esta disputa pudo seguir su curso pese a los bajos recursos financieros, normativos y humanos del ayuntamiento, el cual, sin embargo, ejerció en esta pugna sus medianos recursos políticos y de información. 


\section{G. Cruz Jiménez · C. Cadena Inostroza}

Por su parte, los ixtapenses lucharon por su cometido con pocas ventajas, ya que eran nulos sus recursos financieros, normativos y humanos y solo disponían de poca información acerca de los decretos presidencial y estatal. Salvo la intervención de la UDESIs, que, se infiere, era una Unión que reclamaba se le diera al pueblo el derecho de las aguas de San Gaspar y no a personas de manera ilegal, no existen más evidencias documentales ni testimoniales sobre la organización colectiva del pueblo. En contraparte, gracias a la presión que ejercieron estos actores, pudieron posicionar en la agenda presidencial su inconformidad por la inequitativa distribución de los beneficios derivados de las aguas termales, por lo que su recurso político fue mediano.

Aunque podría suponerse que el gobierno municipal defendió los derechos del pueblo como beneficiario de los borbollones de Santa Catarina, se deduce que su verdadero interés fue económico, pues si esas aguas hubieran sido concesionadas a particulares, las autoridades habrían dejado de percibir recursos por su administración y, en consecuencia, resultarían afectados sus verdaderos intereses. Este argumento se fortalece con el hecho de que, tras perder San Román la querella, el gobierno ixtapense elaboró años después, en 1956, el reglamento del Comité de Administración del balneario, con lo cual quedó como administrador formal tanto de los manantiales como de las recaudaciones por su uso, lo que le significó importantes ingresos adicionales respecto al monto que recibía por concepto de presupuesto federal y estatal (Ricaurte, 2001, pp. 90-91, 102; LRDA).

Se infiere que otro factor que influyó en que la solicitud de San Román Chávez no prospera fue que el gobernador calculó las repercusiones sociales de dar marcha atrás a las disposiciones que él mismo había decretado, lo cual contravendría sus objetivos políticos, por lo que decidió no respaldar, al menos en este caso, el propósito del empresario. Sin embargo, este ya había iniciado su juego político para beneficiarse de una acción más redituable que le garantizaría el monopolio de la oferta turística: la concesión de las aguas termales de San Gaspar.

\subsection{La concesión de las aguas termales de San Gaspar}

Al perder la disputa legal sobre los borbollones de Santa Catarina, Arturo San Román no pudo extender su oferta turística, ni acumular más riqueza y poder, pues el gobierno municipal es, hasta la fecha, el administrador de esos manantiales y los pobladores son los beneficiarios de su uso, aunque no de manera exclusiva, ya que, al construirse el balneario municipal en ese lugar, está abierto al público en general.

No obstante, el empresario tuvo éxito al obtener la concesión de arrendamiento del balneario de San Gaspar, que estaba en manos de José Reynoso, quien disponía de recursos financieros, políticos y normativos, pero que resultaron insuficientes comparados con los de San Román. El hecho de que Reynoso perdiera poderío en este curso de acción respecto al anterior corrobora que las redes no son idénticas en un proceso que en otro ante la diferencia de recursos de sus actores (Bressers, 1998, p. 85). 
No existen soportes documentales ni testimoniales de que Reynoso haya puesto algún tipo de resistencia frente a tal disposición que evidentemente le afectó, por lo que sus objetivos e intereses no resultaron compatibles con los de San Román ni con los del gobernador que apoyó al empresario, de ahí que fuera nula la cooperación entre el mandatario y José Reynoso, quien a su vez tampoco la tuvo con San Román ni con el pueblo.

A pesar de este triunfo de San Román, el más importante fue cuando gracias a sus relaciones con el gobernador Isidro Fabela (LRDA) obtuvo además la concesión de las aguas termales de San Gaspar, pues a partir de la explotación de este recurso amasó la fortuna que hoy en día administra su familia y que le permitió a él primero y luego a sus descendientes influir en el perfil turístico de Ixtapan de la Sal, al consolidar su emporio.

Una versión sobre el motivo de su influencia es que "por haber sido un importante 'talamontes' o maderero nacional, Arturo A. San Román estableció vínculos con la entonces Secretaría de Agricultura” (LRDA). A esta institución le correspondía legalmente otorgar la concesión de aguas termales, aunque, en la práctica, tal facultad la ejercía el presidente, en ese entonces Manuel Ávila Camacho. Se infiere que el gobernador Isidro Fabela intercedió ante su amigo el presidente a favor del empresario, quien a cambio de obtener este beneficio apoyaría directamente el proyecto del mandatario estatal, por lo cual fue alta la compatibilidad de objetivos e intereses de ambos, al igual que su cooperación.

El hecho de que el empresario estuviera a expensas de la intercesión de Fabela para ser favorecido con las aguas termales de San Gaspar hizo que dependiera de manera importante del Ejecutivo estatal, quien presuntamente habría exhibido una mediana dependencia por los supuestos beneficios económicos que obtuvo del empresario:

"Con dinero baila el perro" y así Isidro Fabela le concedió a Arturo Alfredo San Román Chávez la franquicia de explotación de las aguas termales de San Gaspar [LRDA].

Por lo tanto, los objetivos e intereses de ese particular tuvieron nula compatibilidad con los del gobierno municipal, que así dejó de administrar de forma definitiva el balneario que antes arrendaba; tampoco fueron afines con los del pueblo, el cual debió soportar una vez más que personas ajenas a la comunidad resultaran favorecidas con los mejores borbollones. Por consecuencia, los intereses de los ixtapenses y del ayuntamiento también se contrapusieron de algún modo con los de Fabela, que por una parte los benefició con la disposición correspondiente a los manantiales de Santa Catarina, pero no así en ese caso; esto refuerza lo que ya se había expuesto respecto a que sus intereses tuvieron una compatibilidad media.

En este marco, el gobernador puso nuevamente en juego sus altos recursos políticos, normativos, humanos y de información para favorecer al patriarca de los San Román, quien a su vez ejerció los suyos en materia financiera, política, humana y de información para obtener tal beneficio, que al ser de carácter normativo acrecentó sus recursos. Según Ricaurte (2000), esa concesión representa un monopolio sostenido mediante mecanismos de poder e influencia económica. 


\section{G. Cruz Jiménez · C. Cadena Inostroza}

Ya con la concesión de los borbollones de San Gaspar y luego de construir los inmuebles turísticos que le permitirían consolidar sus intereses, Arturo San Román necesitaba más apoyo y lo recibió una vez más de Isidro Fabela, quien recurrió a su fortaleza política al inaugurar el hotel, el balneario y el spa del inversionista. Aunque no está claro el tipo de apoyo que le brindó el mandatario estatal, se infiere que fue económico y político, acorde con los intereses del empresario, quien resultó el mayor beneficiado con las acciones emanadas del sector público.

El atractivo más importante en la localidad era su balneario, complementado por los servicios de hospedaje y del spa, que recibieron mayor afluencia gracias a la carretera federal Toluca-Ixtapan, cuyo funcionamiento en 1945 estuvo aparejado al decreto de Ixtapan de la Sal como zona turística, emanado también de la administración de Fabela. De acuerdo con Hernández (1998, p. 82), este vinculó el quehacer estatal con el proyecto económico nacional, y una de las acciones que puso en marcha para avanzar hacia ese fin fue su programa de carreteras.

A decir de los pobladores, San Román Chávez hizo una significativa aportación económica para la carretera con el propósito de fomentar el turismo hacia su hotel y balneario (Ricaurte, 2000, p. 83). Petronio Valencia Arizmendi (PVA), subdirector municipal de Turismo, señaló que previamente el empresario promovió la plantación de sauces llorones por donde después cruzó esta vía. ${ }^{2}$ De esa serie de acciones queda de manifiesto que aun cuando en cierto momento el objetivo del empresario resultó afectado por los decretos que evitaban la concesión de los borbollones de Santa Catarina a particulares, el respaldo que recibió posteriormente por parte de los gobiernos estatal y federal superaron en mucho las pérdidas por aquellas disposiciones oficiales.

De acuerdo con Luis Enrique Morán Noreña (LEMN), administrador de Bungalows Lolita; Benjamín Sotelo Domínguez (BSD), subgerente general de Hotel Villa Vergel, y PVA, ese beneficio le permitió allegarse de recursos políticos al vincularse con personajes de ese ámbito, sin que esté claro el origen de esas relaciones, presuntamente fomentadas con las casas que obsequió a gobernadores y presidentes.

El sentir de una parte de los prestadores de servicios sobre su actuación en la localidad se refleja en las palabras del propietario de un hotel de mediana categoría:

A él le debemos que Ixtapan esté así (en referencia a su perfil turístico); ahora los prestadores "cosechan lo que él sembró" [BSD].

El empresario murió en 1977 y con él aquel turismo de salud y descanso que promovió. Sus hijos Arturo y Roberto San Román Widerkehr, quienes ya también fallecieron, recibieron en herencia el balneario y el Hotel Ixtapan, respectivamente. El primero impulsó el parque acuático, hasta convertirlo en uno de los diez más importantes en el ámbito internacional y el principal motivo de visita a la localidad. El segundo participó de la tendencia

2 San Román Chávez fundó la Escuela de Arboricultura Práctica, donde se estableció el sistema de internado para alumnos de distintos municipios, cuyo primer fruto fue precisamente la mayoría de los árboles sembrados en ambos lados de la vialidad hasta llegar al municipio de Metepec (Guadarrama, 2004). 
hacia el turismo de negocios y con uno de sus herederos promovió la construcción del fraccionamiento turístico residencial Country Club Gran Reserva. Como impacto directo de todo ello, se transformó el perfil socioeconómico de la población (Ricaurte, 2000), hecho que corresponde a la segunda etapa de su desarrollo turístico (de 1980 a la fecha).

\section{Resultados}

El turismo, una de las principales actividades en Ixtapan de la Sal, fue el eje común en torno al cual convergieron, durante los dos cursos de acción abordados, personajes que definieron de manera individual o como grupos de interés sus objetivos, que no necesariamente estuvieron relacionados con esta actividad, pues en algunos casos más bien obedecieron a satisfacer -por medio de ella- sus intereses en particular de naturaleza política y de predominio económico; este último no en un sentido exclusivo de generar dividendos financieros, sino supremacía en el establecimiento de cotos de poder. Sin embargo, la consolidación de esos objetivos e intereses fueron los que finalmente moldearon el actual perfil turístico de Ixtapan de la Sal.

Tal complejidad de relaciones e interrelaciones entre unos y otros actores propició la formación de un red de política pública que se transformó de un curso de acción a otro y en la cual los intereses de sus participantes motivaron su actuación, así como las estrategias que desplegaron como parte de su juego político, entre ellas relaciones de cooperación con otros personajes con los que en ocasiones sus objetivos e intereses no convergieron por completo, pero que, al no contraponerse, pudieron establecer un vínculo que los benefició en forma recíproca, a veces en perjuicio de otros actores, no necesariamente los más débiles, aunque en términos generales así fue.

En los años treinta, una década antes del despegue turístico en Ixtapan de la Sal, el ayuntamiento estaba prácticamente relegado y subordinado a las políticas provenientes de los ámbitos federal y estatal, panorama que se mantuvo por años, sin que en la época actual el gobierno municipal haya logrado una verdadera autonomía, ni en lo financiero, ni respecto a la toma de decisiones, tanto en materia turística, como en lo general.

En la década de los cuarenta, la figura presidencial ejercía un papel predominante que se refleja en la red y que tuvo repercusiones vinculadas con el turismo; el ejemplo más representativo fue la concesión de aguas termales que obtuvo Arturo San Román Chávez, gracias a la intercesión del gobernador Isidro Fabela ante el presidente Manuel Ávila Camacho.

Aquí se corrobora el hecho de que la autoridad pública no ejerció su predominio para delinear políticas a favor del turismo, sino para propiciar las condiciones que permitieran a un particular iniciar, a partir de la explotación de las aguas termales, lo que más tarde se convertiría en un emporio.

Asimismo, prevalecieron asimetrías de poder entre los sectores público, social y privado en Ixtapan de la Sal, debido a que desde su inicio hubo condiciones de inequidad respecto a los intereses que estuvieron en juego a lo largo del periodo analizado. Esa condición obedeció a que no hubo un balance real en la participación y decisión de los 


\section{G. Cruz Jiménez · C. Cadena Inostroza}

integrantes de esos sectores y, por lo tanto, sus intereses no estuvieron representados de manera equitativa, lo cual condujo al desequilibrio en la toma de decisiones que favoreció a los más poderosos. Lo ocurrido en los cursos de acción examinados en esta primera etapa de desarrollo turístico siguió teniendo la misma lógica en la conducción gubernamental en las décadas posteriores y prevalece en la actualidad, cuestionan Vicente Lagunas Madrid, gerente de Villas de Belem; Enrique Pérez Nájera (EPN), gerente del Hotel Belisana; Javier Madrid Hernández (JMH), expresidente del Comité Ejecutivo Municipal del Partido de la Revolución Democrática; y Julio César Sergio Becerril (JCSB), excandidato a la alcaldía por el Partido Acción Nacional.

En ese sentido, otra de las mayores ventajas que obtuvo la familia San Román fue la concesión de la mayor parte del agua potable, cuyo volumen sobrepasa incluso la que recibe el gobierno municipal para abastecer a la población (incluidos los prestadores de servicios), lo cual le ha supuesto ventajas, en especial en época de sequía, que coincide con la temporada vacacional, según testimonios de Fidel López Ronces (FLR), exdirector del Organismo Público Descentralizado de Carácter Municipal para la Prestación de los Servicios de Agua Potable, Alcantarillado y Saneamiento de Ixtapan de la Sal (Odapas); Juan Morales Álvarez (JMA), auxiliar de Odapas; y Víctor Manuel Rodea Ruiz (VMRR), exdirector de Del Rey Inn Ixtapan de la Sal.

En suma, los actores que desplieguen un juego político basado en la compatibilidad de objetivos e intereses con otros integrantes, dispongan de mayores y mejores recursos, establezcan relaciones de cooperación que en su conjunto les permita desarrollar interacciones fuertes en la red, tendrán mayores posibilidades de influir en la orientación del proceso decisorio y, en consecuencia, podrán consolidar cierta política a su favor (Cruz, Serrano-Barquín y Zizumbo, 2010), como ocurrió en el caso de estudio.

En las figuras 1 y 2 se representa la red de política pública que se formó respectivamente en los cursos de acción "El arrendamiento del balneario de San Gaspar" y "La confrontación por las aguas termales". En ellos se aprecia cómo se transformó entre uno y otro curso, al integrar a diferentes actores, quienes ocuparon una posición en la red dependiendo de su influencia durante el proceso decisorio. También se observan las relaciones o inexistencia de ellas entre sus integrantes, al igual que la intensidad de su vínculo, sea negativo o positivo, de acuerdo con los intereses que se jugaron. 


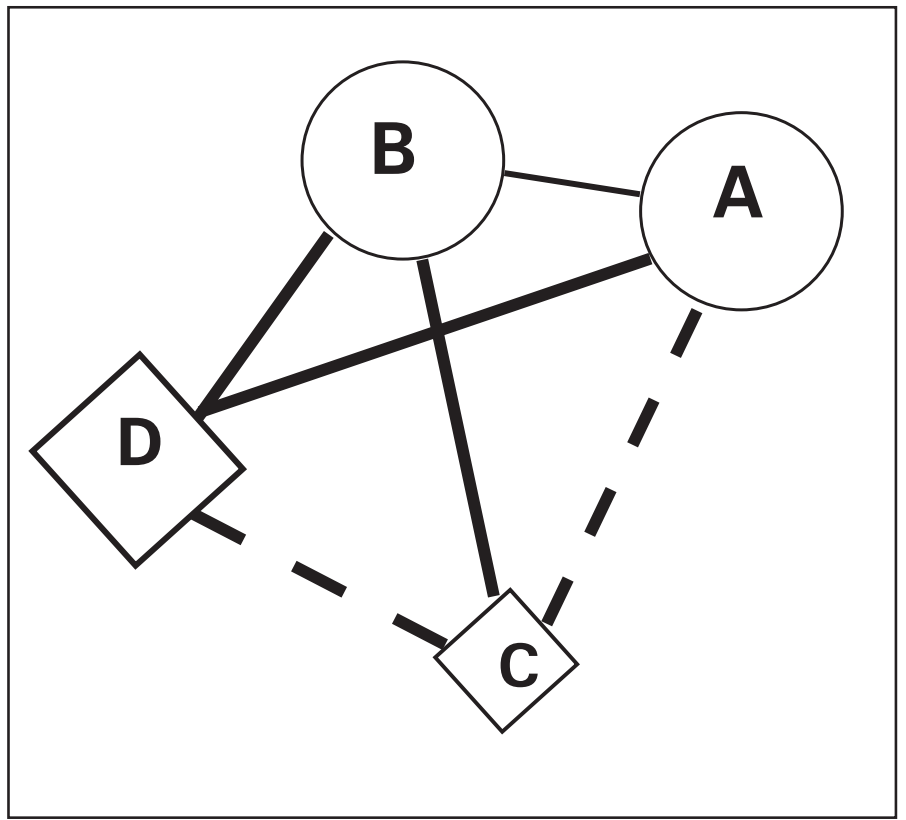

Fuente: Elaboración propia con base en la información de las variables analizadas

\section{Actores participantes en la red} de política pública:

A Filiberto Gómez, gobernador del Estado de México (1929-1933);

B Gobierno municipal 1932;

C Erasmo Hernández, arrendatario del balneario de San Gaspar;

D José Reynoso, arrendatario del balneario de San Gaspar.
Sectores en la red:

Público<smiles>c1ccccc1</smiles>

Privado

Tipo e intensidad de la relación:

Alta positiva

Alta negativa $\mathbf{-}-\boldsymbol{-}-\boldsymbol{-}$

Media positiva

Influencia de los actores en la red:

Influencia mediana<smiles>C1CCCCCC1</smiles><smiles>C1CC2CCC12</smiles>

Influencia baja

Figura 1. Red de política pública "El arrendamiento del balneario de San Gaspar" 


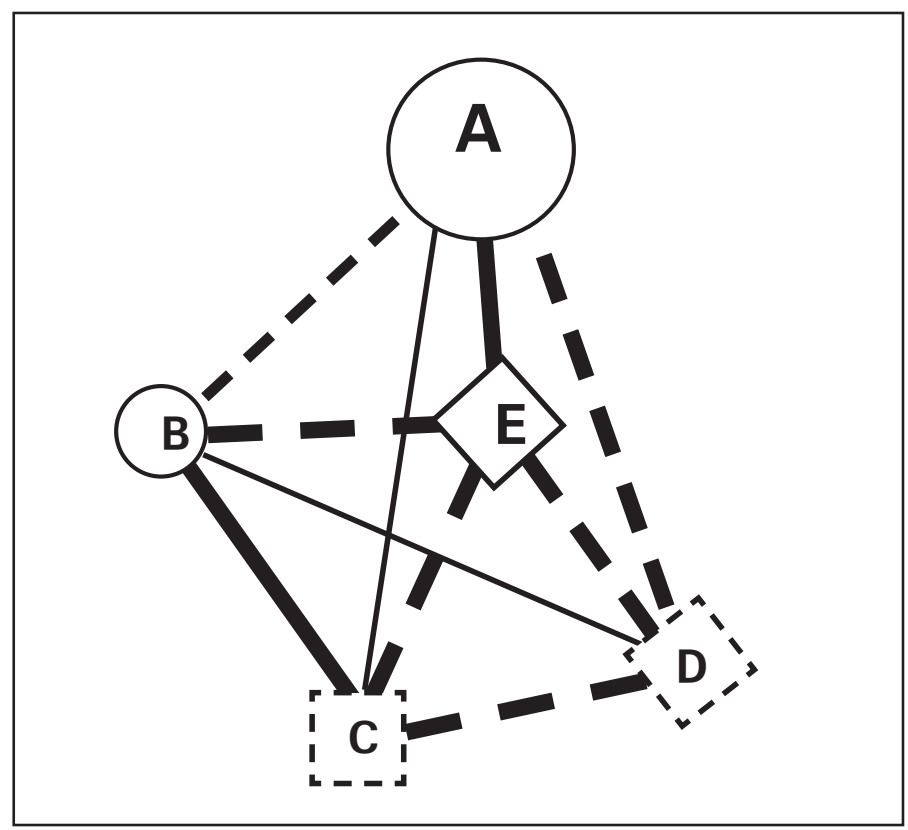

Fuente: Elaboración propia con base en la información de las variables analizadas

\section{Actores participantes} en la red de política pública:

A Isidro Fabela, gobernador del Estado de México (1942-1945);

B Gobierno municipal 1944;

C Pueblo de Ixtapan de la Sal;

D José Reynoso, arrendatario del balneario de San Gaspar en 1932;

E Arturo Alfredo San Román Chávez, arrendatario del balneario de San Gaspar y concesionario de las aguas termales de San Gaspar en 1947.

\section{Sectores en la red:}

Público $\bigcirc$ Social

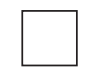

Privado

Tipo e intensidad de la relación:

Alta positiva

Alta negativa

Media positiva

Influencia de los actores en la red:

Influencia mediana

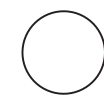

Influencia baja

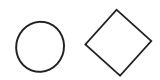

Influencia nula

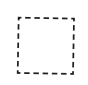

Figura 2. Red de política pública "La confrontación por las aguas termales" 


\section{Conclusiones}

Los supuestos teóricos del ERPP dieron posibilidades de abordar una realidad a partir de un complejo entramado de relaciones entre actores pertenecientes a diferentes sectores, cuya influencia contribuyó en gran medida a delinear el perfil turístico de Ixtapan de la Sal, donde fueron decisivos los dos primeros cursos de acción correspondientes a la primera etapa de su desarrollo en esta materia.

No obstante, el propio enfoque representa un desafío metodológico al ser limitada la producción académica en México sobre casos empíricos, en particular vinculados con el turismo, aunque paulatinamente se aprecian mayores esfuerzos en este sentido. Un aspecto más de este reto es que por ser las relaciones las que dan sustento a tal enfoque, su análisis para el caso abordado tuvo ciertas limitantes ante la ausencia física de los protagonistas del turismo en esa época.

El hecho de recurrir a otros personajes que aportaran su testimonio o la búsqueda documental podría hacer la información propensa a la subjetividad, lo que conlleva el riesgo de interpretaciones erróneas y, por ende, distorsionadas acerca de los hechos abordados; pese a ello, cuestiones como estas deben afrontarse para ampliar el panorama sobre los habituales estudios sustentados en aspectos lineales.

Cabe resaltar que, a pesar del uso de matrices relacionales, el resultado cuantitativo no siempre fue el más fiel a la realidad. Si bien el o los personajes que obtuvieron los puntajes más altos debieron ser interpretados en un primer momento como los más importantes en la red y, por tanto, los que ejercieron mayor influencia, no siempre fue así. Sus vastos recursos, nula o mínima conflictividad con otros participantes, fueron variables que les dieron un alto puntaje, aunque en realidad no hayan ejercido el mayor predominio.

De hecho, aquel que fue más influyente, no en términos cuantitativos sino reales, observó una marcada conflictividad con otros porque, como parte de su juego político, desplegó estrategias para hacer valer sus intereses muchas veces a costa del resto. No obstante, y como se argumentó a lo largo del documento y se constata en la representación gráfica de las redes correspondientes a los cursos de acción analizados, la constante en ambos fue la representación asimétrica de los distintos sectores y, en consecuencia, en la toma de decisiones.

Porras (2016, p. 91) argumenta que cuando las redes de política pública se conforman por actores o instituciones provenientes de varios sectores como del gobierno, la sociedad organizada o los mercados, y adquieren cierta capacidad para resistir las directrices del Estado, pueden ser consideradas redes de gobernanza (lo cual no sucedió en estos casos).

Son precisamente enfoques como el de la gobernanza los que también pueden apoyar análisis de naturaleza turística, actividad que por su multidimensionalidad, en ocasiones las políticas convencionales no alcanzan a darle respuesta. En este sentido se integran capacidades no gubernamentales en una nueva forma de gobernar, donde se observa la existencia de agentes privados, sociales y comunitarios capaces de autorregularse y resolver sus problemas. 


\section{G. Cruz Jiménez · C. Cadena Inostroza}

La gobernanza permite reflexionar sobre la participación local en el diseño, implementación y evaluación de las políticas públicas que conciernen al turismo (Roldán, Corbo y Castellucci, 2017, p. 17). Por tanto, en la medida en que sea posible la incorporación de los diferentes actores en un esquema equilibrado de participación, mayores serán las posibilidades de promover una práctica turística más efectiva.

\section{Fuentes consultadas}

Aguilar, L. (1992). Problemas públicos y agenda de gobierno. Estudio introductorio y edición (Antologías de Política Pública). México: Miguel Ángel Porrúa.

Aguilar, L. (2003). El estudio de las políticas públicas. Estudio introductorio y edición (Antologías de Política Pública). México: Miguel Ángel Porrúa.

Aguilar, L. (2007). El estudio de las políticas públicas (Antologías de Política Pública). México: Miguel Ángel Porrúa.

Arizmendi, L. (1999a). Monografía Municipal Ixtapan de la Sal, Gobierno del Estado de México. Toluca: Asociación Mexiquense de Cronistas Municipales.

Arizmendi, L. (1999b). Ixtapan de la Sal y su promoción como centro turístico 1945-1995 (Tesis de licenciatura en Turismo). Universidad Autónoma del Estado de México, Toluca.

Becerril, J. (1988). Los recursos geográficos y perspectivas para el desarrollo turístico de Ixtapan de la Sal (Tesis de licenciatura en Geografía). Universidad Autónoma del Estado de México, Toluca.

Bressers, H. (1998). The choice of policy instruments in policy networks. En D. Marsh, Comparing Policy Networks (pp. 85-105). Filadelfia: Open University Press.

Cadena, C. y Cruz, G. (2006). Políticas públicas municipales, relación de actores y desarrollo turístico en dos localidades del Estado de México (Documentos de Investigación, 113). Zinacantepec: El Colegio Mexiquense.

Castillo, R. (1995). Caracterización de la demanda turística que fluye al poblado de Ixtapan de la Sal (Tesis de licenciatura en Turismo). Universidad Autónoma del Estado de México, Toluca.

Cruz, G. (2014). El turismo como punto de conflicto y acuerdo en las redes de política pública. El caso de Ixtapan de la Sal, Estado de México. Zinacantepec: El Colegio Mexiquense.

Cruz, G., Serrano-Barquín, R. y Zizumbo, L. (2010). Redes de política pública y turismo en San Miguel Almaya. ¿Promotoras o limitantes del desarrollo local? Estudios y Perspectivas en Turismo, XIX(5), 792-811. Recuperado de http:/ / www.redalyc.org/ articulo.oa? id= 180717609012

Cruz, G., Serrano-Barquín, R., Mejía, C., Mejía, L. E. y Reza, J. (2010). Turismo y sustentabilidad; la complejidad del proceso decisorio en San Miguel Almaya. Ra Ximhai, VI(3), 379-392. Recuperado de http://www.revistas.unam.mx/index.php/rxm/article/ view $/ 24594$

Flores, A. (1987). Monografía municipal Ixtapan de la Sal. Toluca: Gobierno del Estado de México. 
Franco, J. (2013). Diseño de políticas públicas. México: IEXE Editorial.

García, J. (2000). Iztapan en el siglo xvı, Ixtapan de la Sal. En Cuadernos Municipales (pp. 31-70). Zinacantepec: El Colegio Mexiquense.

González, A. (2004). El anfitrión como actor social en el turismo. Reflexiones desde el caso de Ixtapan de la Sal, México. Revista de Ciencias Sociales, III(105), 155-168. Recuperado de https://revistacienciassociales.ucr.ac.cr/images/revistas/RCS105/ 10Gonzalez.pdf

Guadarrama. (2004). Arturo San Román. Ixtapan de la Sal, México.

H. Ayuntamiento de Ixtapan de la Sal. (1931). Archivo Histórico Municipal, Ixtapan de la Sal, sección Presidencia, vol. 2, exp. 1. Ixtapan de la Sal, México.

H. Ayuntamiento de Ixtapan de la Sal. (1932). Archivo Histórico Municipal, Ixtapan de la Sal, sección Presidencia, vol. 2, exp. 7. Ixtapan de la Sal, México.

H. Ayuntamiento de Ixtapan de la Sal. (2016). Atlas de Riesgos Municipal. Toluca: Coordinación General de Protección Civil del Estado de México. Recuperado de http:// ixtapandelasal.gob.mx/.../Atlas_IxtapanZdeZlaZSalZ2016...

Hernández, E. (2015). Análisis de redes sociales para el estudio de la gobernanza y las políticas. México: Centro de Investigación y Docencia Económicas.

Hernández, O. (2001). Impactos del boulevard turístico Ixtapan de la Sal Tonatico (Tesis de licenciatura en Turismo). Universidad Autónoma del Estado de México, Toluca.

Hernández, R. (1998). Amistades, compromisos y lealtades: líderes y grupos políticos en el Estado de México, 1942-1993. México: El Colegio de México.

Instituto Nacional de Estadística y Geografía. (2010). Censo de Población y Vivienda 2010. Recuperado de http://www.beta.inegi.org.mx/proyectos/ccpv/2010/

Klijn, E. (1997). Policy networks: An overview. En E. Kickert, E. Klijn y F. M. Koppenjan, Managing Complex Networks. Strategies for the Public Sector (pp. 14-34). Londres: Sage.

Martínez, J. (1997). El esquema laboral del turismo en Ixtapan de la Sal (Tesis de licenciatura en Turismo). Universidad Autónoma del Estado de México, Toluca.

Meny, I. y Thoenig, J. C. (1992). Las políticas públicas. Barcelona: Ariel.

Montecinos, E. (2007). Límites del enfoque de las políticas públicas para definir un problema público. Cuadernos de Administración, XX(33), 323-335. Recuperado de http://www.scielo.org.co/pdf/cadm/v20n33/v20n33a 14.pdf

Porras, F. (2012). Gobernanza y redes de política pública en espacios locales de México. México: Instituto de Investigaciones José María Luis Mora.

Porras, F. (2016). Gobernanza. Propuestas, límites y perspectivas. México: Instituto de Investigaciones José María Luis Mora.

Ricaurte, C. (2000). Sustentabilidad y turismo: el caso de Ixtapan de la Sal. El Periplo Sustentable, 3. Recuperado de www.uaemex.mx/plin/psus/rev3/ceditorial.html

Ricaurte, C. (2001). Turismo, sustentabilidad y gestión local en el municipio de Ixtapan de la Sal (Tesis de maestría en Estudios Socioeconómicos y Físicos del Turismo). Universidad Autónoma del Estado de México, Toluca.

Roldán, N., Corbo, Y. y Castellucci, D. (2017). Una aproximación al estado del arte en gobernanza y turismo, 2010-2015. En G. Cruz (coord.), Turismo y gobernanza. ¿En dónde estamos? Aproximaciones teóricas y empíricas (pp. 15-36). Universidad 


\section{G. Cruz Jiménez · C. Cadena Inostroza}

Autónoma del Estado de México. Recuperado de http://ri.uaemex.mx/handle/20.500.11799/67922

Van Meter, D. y Van Horn, C. (2003). El proceso de implementación de las políticas. Un marco conceptual. En L. Aguilar (ed.), La implementación de las políticas (Colección de Antología de las Políticas Públicas, pp. 99-124). México: Miguel Ángel Porrúa.

Zabaleta, D. (2006). Espacios multiorganizativos de políticas y conformación de redes de políticas en los municipios urbanos mexicanos. El caso de la política de protección y conservación del Centro Histórico de Morelia, Michoacán (Tesis de licenciatura en Administración Pública). El Colegio de México, México. 